\section{ASSESSING RURAL DEVELOPMENT: INDICATORS BASED ON HERITAGES OF THE PEASANTRY ANALYTICAL FRAMEWORK}

\author{
Fabio Pachon* \\ Wolfgang Bokelmann ** \\ and \\ César Ramírez ${ }^{* * *}$
}

\begin{abstract}
The meaning of rural development has been widely discussed worldwide among the policy makers, academics and peasants. Rural development aims to improve the quality of life, while respecting the rights of all rural inhabitants. This paper describes the indicators selected to assess rural development at the household level and classifies them according to the analytical framework'Heritages of the Peasantry' to facilitate the analysis of their connections. Delphi methodology was used to select the most relevant indicators, which included the participation of a panel of experts on the online survey, statistical analysis and a field test. The results show that the 23 indicators selected focused on productive, social, infrastructural, commercial, institutional and environmental concerns. The indicators chosen cover a broader range of rural development issues than previous studies and the methodology used to select them was inclusive of different stakeholders involved. However, restriction on technology access in the countryside was the bottleneck to reach the contribution of more rural inhabitants.
\end{abstract}

\section{Introduction}

Rural development has the characteristics of 'Wicked Problems' because it is a complicated situation and an adverse circumstance that involves many trials and tribulations; it engages a lot of people and becomes a challenge to tackle. A 'Wicked Problem' is complex and hard to be portrayed or answered. It is multi-causal, improperly comprehended and has many

* Department of Rural Development, Universidad Nacional de Colombia, Build 500, off. 235. Bogotá, Colombia, E-mail: fapachona@unal.edu.co

** Albrecht Daniel Thaer- Institut für Agrar- und Gartenbauwiss, Humboldt Universität zu Berlín, Invalidenstraße 42. Berlin, Germany.

***Direction of Regional Centres, Universidad Autónoma Chapingo, Chapingo, Mexico.

The authors are highly grateful to the German Academic Exchange Services DAAD, COLCIENCIAS, Education Ministry of Colombia for financial support to current research. The authors also wish to thank all the participants in different steps of the methodology and the anonymous referees for their valuable suggestions in improving the paper.

Journal of Rural Development, Vol. 36, No. 4, October- December : 2017 
interdependencies. It is beyond the capacity of governments and organisations to solve. The stakeholdersinvolved frequently disagree on the ways to address and manage these problems. Policies should overcome them. However, their effects occasionally may further complicate the situation. That is why a chronic failure of policies is one of the characteristics of 'Wicked Problems'.

Rural development has not had a precise formulation. Several perspectives, from the technocratic to the political viewpoints, havetried to address rural development problems offering just partial alternatives. The technocratic approach isfocused on economic and productive answers to rural development challenges. On the contrary, the sociological approach highlights the needs of rural people.The socio-technocratic approach emphasises on the competitiveness and the political approach on the rights of the rural population (Pachón-Ariza, Bokelmann, \& RamírezMiranda, 2016b).

These alternatives are not correct or incorrect; they are just incomplete and have influenced the public policy based on economic pattern. That is why they have often led to unexpected consequences (Brown, Harris, \& Russell, 2010), which sometimes are adverse to the environment, but especially to the rural peoplewho remain isolated, illiterate and trapped in poverty.

An option to tackle the 'Wicked Problem' is transdisciplinary approach that addresses the entire problem and connects the interrelationships among a complete range of causative influences. It tries to integrate all the problems and find multi dimensional solutions. For thispurpose, it musttakeinto account asmany stakeholders and thoughts as possibleto identify all the related matters. To do this, we need to determine the indicators that reflect the reality of rural territories through an inclusive methodology and analyse these factors in a comprehensive framework such as heritages of the peasantry.

Heritages of the peasantry ${ }^{1}$ is an analytical framework proposed to address rural development in a holistic way, motivated by the fact that, so far, the proposals have focused on specific topics instead of an integral vision. Initially, it is important to remark the rural development goal. In simple words, it aims to improve the quality of living while respecting the rights of all rural inhabitants. Forthe purpose of reaching this goal,the peasantry must identify, appraise and use all the heritages that they have. Accordingly, the peasants hold seven kinds of heritages: cultural, social, economic, human, institutional, natural, and physical. The ancient knowledge, traditions, customs, history, behaviours, beliefs and production manners of the peasantry become a heritage and based on it, they can improve their quality of life and ensure that their rights are respected.

Heritages, analysed in the space of the patrimony, are those structures, concepts, principles and attitudes considered as momentous by a social group because they guarantee the survival of its culture and identity (Figure 1). For the current analytical framework, heritage and patrimony are pondered in the same 
mode; however, both terms are contemplated in a different scenario from one of the 'capitals'. As heritage and patrimony belong to culture and identity, they do not have a monetary value.
Hence, they are beyond the market; people cannot buy or sell them because identity and culture are not commodities.

Figure 1: Importance of Heritages of the Peasantry

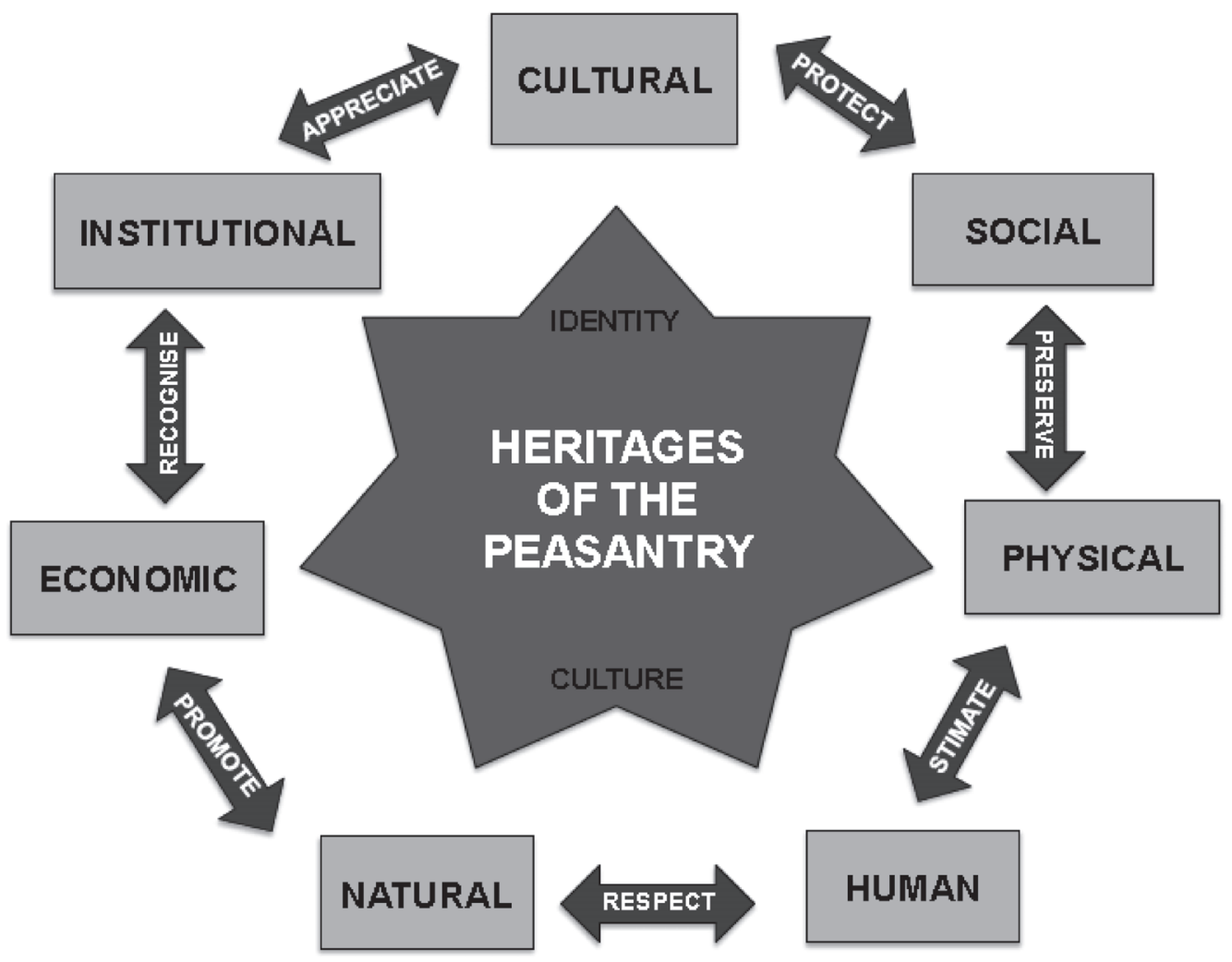

Indicators of rural development, analysed through the analytical framework of heritages of the peasantry, could be an alternative to achieve a strategy through which rural inhabitants, in conjunction with governments, could construct consensual public policies. The goal of these systems must be to improve the quality of life while respecting the rights of all rural inhabitants.
Previous investigations on the issue of rural development indicators have been conducted throughout the world. Some of these enquiries have taken sustainability or environmental approaches into consideration (Alfsen \& Greaker,2007; Ciegis, Ramanauskiene, $\&$ Startiene, 2015; Schultink, 2000). Some have considered a productive point of view (Binder, 
Feola,\&Steinberger,2010;D. Rigby,Woodhouse, Young,\&Burton,2001;Rossing et al.,2007), while others have focused on particular themes such as infrastructure, electricity or clean water access (Barrios,2008;Caschili,De Montis, \&Trogu,2014; Ilskog,2008). However,just a few have taken into account a broader range of topics. Hence, the measurement of rural development in an integral sense has been insufficient. A possible explanation for this statement is because of the complexity of the rural development grounds.

This paper seeks to describe the methodology used to select rural development indicators based on the analytical framework of heritages of the peasantry in order to widely address a 'Wicked Problem' like rural development.

\section{Focus of Previous Research on Rural Development Indicators}

The kind of previous research focused on rural development indicators can be classified into four categories: firstly, those studies that privilege environmental matters; secondly, those related to productivity; thirdly, those focused on infrastructure issues; and finally, integrative and holistic studies. Following is a short description of each one.

Focus on Sustainable Development and Sustainability: In the international literature many researches deal with the sustainable development indicators. The basis of sustainable development is the Brundtland statement and remarks on the economic, social and environmental pillars defined by the World Summit on Sustainable Development in 2002.
Human beings are at its core. That means an anthropocentric and pragmatic orientation concentrated on people and their welfare. Human life shall remain in a kind of balance among these pillars, featured by the harmony among health, productivity and nature. Human needs constitute the basic concern. Regarding human needs,Maslow'sTheory and Human Scale Development perspective provide dissimilar viewpoints on this issue; primarily distinguishing between the kind and quantity of requirements and the ways of their satisfaction.

In this scenario, some authors have proposed different types of indicators to measure both sustainability and sustainable rural development. Farrow \& Winograd (2001) measured rural sustainability in Central America based on a land use model.The most interesting issue of this research is the use of Geographical Information Systems (GIS), combining several kinds of data with a more active tool. The importance of use of GISisthe likelihood forpolicy makers to define better policies based on the transformations over time and space.

Focus on Production: The current feature of this kind of research on productive matters is environmental concerns and multi-functionality of agriculture. Multi-functionality, in essence, means that rural areas offer not only food and raw materials, butalso other kinds of public goods such as landscapes, protected lands, water oxygen, spacesfor relaxation, entertainment and so on. In this scenario, Rossing et al., (2007) described an interesting set of indicators to assess the multi-functionality of agriculture in France, 
Germany and The Netherlands. Based on this research, Mittenzwei et al., (2007) proposed indicators relating assessment of this multifunctionality with the Common Agricultural Policy Regional Impact Analysis (CAPRIA).They organised indicatorsinto fourtypes: food security; rural viability, landscapes and environment, focusing on topics such as farmers' surplus, farmland necessities, feed requirements and nutrient requirements.

Similarly, Cowell \& Parkinson (2003) conducted a research based on productive indicators such as 'land area and energy consumption' to reorganise food production in the United Kingdom. After a sophisticated evaluation of different types of crops and according to the consumption habits of the British society, they concluded that it is preferable to import some foodstuffs rather than produce them in the UK.' Those are some examples of productive indicators used to assess rural areas beyond the conventional analysis based on crops productivity.

Focus on Infrastructure: Another crucial topic related to rural development is physical infrastructure. Regarding this problem several researchers have conducted, especially in developing countries, investigations to assess the advantages to construct physical infrastructure in rural areas. According to Shen et al., (2012), the current situation in developing countries is that investment in infrastructure is lower in the countryside than in urban ones. This condition could be different in the rural areas located near the principal cities. On the contrary, areas located far away from medium or big cities usually do not have substantial investments to improve the quality of their infrastructure. Some examples are unpaved roads, reduced access to clean water, absence of sewage systems, poor electricity or insufficient health centres and school buildings. The research suggests that a good infrastructure generates economic, social, environmental and ecological benefits. Equally, they concluded that 19 indicators should be taken into account at the moment of defining investment projects to develop infrastructure in rural areas.

Focus on Integrative Point of View: Finally, it is important to mention examples to evaluate rural development in a holistic way. The proposal of Kageyama (2004), in addition to defining rural development, also aims to measure it. She highlights the difference between the terms 'rural'and 'agricultural'. Their multi-functionality and pluriactivity characterise rurality. The investigation remarks that rural and urban are inter-connected and their boundariesare difficult to define. Despitethisfact, the author argues that rural development matters are extremely complex, it isnecessary to take into consideration all the factors involved to approach these problems. In thisscenario, shesuggests a network of indicators to measure rural development in Brazil. She divided them into four groups: environment, population and migration, economics, and social well-being. The main conclusion is that beyond the increment of incomes, the improvement of infrastructure or the rising productivity, rural development needs a multi-dimensional approach to comprehend its real complexity. Based on this investigation, Correa, et al., (2008) used similar indicators to 
evaluate the rural regions in North East and Southern Brazil.Similarly,Melo and Parré (2007) constructed an Index of Rural Development for townsin theState of Paraná (Brazil). Even though both studies share the same principles used by Kageyama, in the last case the authors used indicators for productive topics such as the number of hectares and productivity of corn and soya bean, as well as the number of poisoning cases by agrochemicals.

Bryden, et al., (2002) have done an impressive work to measure rural development in the field of public policies of the European Union. The primary concern of this research was the problem of spatial scale and related data availability.They defined three major groups of indicators: social well-being, economic structure and performance,population and migration. They selected 500 primary indicators and in the end, 55 were chosen. The results showed that despite theenormous investmentsin public policies, data availability in all the member countries differed sharply. Besides, although the general vision of systems holds a territorial approach in many places the persistence of a disciplinary vision was evident.

Some International Institutions such asthe Organisation for Economic Co-operation and Development (OECD), the World Bank (WB) and the United Nations (UN) have defined these kinds of indicators for their work. The OECD has proposed 20 indicators organised around four different topics: social, economic, demographic and environmental (Lehtonen, 2008). Meanwhile, the UN has defined four components of rural development:technology,ecology, society and economy. A successful policy based on these elements should diversify the economy,increase employment, generate access to useful services and avoid migration (United Nations, 2009). The WB approach to reducing rural poverty proposes five indicators: number of households below the poverty level, social and physical well-being, infant mortality rate, gender equity and food security (World Bank,2000).

The conclusion of all these investigations is that beyond the type of indicators used, the availability of data is a serious problem because the collection process is expensive and difficult, to do regularly. Also, the reliability of the information varies according to the place-more complicated to analyse information from distant regions where infrastructure is deficient.

\section{Methodology}

The complexity of some problems requires engaging as many stakeholders as possible to get a broad range of opinions and thus, identify the fundamental indicators that allow recognising as many factors affecting in the case of rural development. The study used Delphi methodology to fulfill this gap. This method ischaracterised "by structuring a group communication process, the process is effective in allowing a group of individuals, as a whole, to deal with a complex problem" (Linstone \&Turoff, 2006:3).

The Delphi method has been employed to tackle the problems which are extremely complex. It has been widely used in economics 
and it is useful to gather the contribution of people with diverse backgrounds, locations and expertise or when time and budget do not allow to organise many meetings (Linstone \& Turoff, 2006). Okoli and Pawlowski (2004) describe deeply the pros and cons of the Delphi methodology showing a detailed example of its application in Sub-Saharan Africa. Similarly, Landeta (2006) evaluated the validity of the method especially in social sciences analysing three studies where experts were contacted to get their judgment to make policy decisions. Based on these suggestions, to improve the method, the current paper used seven steps to identify the main indicators to assess rural development.

1. Literature Review:Initially, 300 indicators were selected based on a comprehensive scientific literature review that measured rural development, sustainable development in the countryside and other rural concerns. Later, the first selection of these indicators was carried out based on relevance and difficulty in measuring them. At the end of this phase, 108 indicators remained.

2 Second Selection of Indicators: The second selection was carried out based on similarities. For example, more than 10 topics related to infrastructure were grouped into one indicator.At the end of this stage, 86 indicators remained.

3. Panel of Experts: The third phase of selection used the methodology of the Vester's Matrix.The Matrix aims to identify the possible influence that, in this case, an indicator could exert on others. Usually, this tool is used to analyse complex problems such as rural development. The result is a classification of the variables in four types: 'Critical Variables', those that have an extensive influence on others, but simultaneously suffer the influence of others.'Active Variables',those that have a broad influence on others, but do not suffer the influence of others. 'Buffer Variables', those that at the same time exert and suffer a minimum impact. Finally, 'PassiveVariables', those that suffer full influence of others, but that exert slight influence on others (Cole, 2006). Participation in Vester's Matrix requires a comprehensive view of rural development issues. That is why 10 experts who belong to a research group with more than 10 years of experience and numerous projects and publications about rural development problems assessed the 86 remaining indicators.

Finally, 37 indicators classified as 'Critical Indicators' remained. The reasons for selecting them were: firstly, the concept of panel of experts about the urgency to makeastrong integration of indicatorsand secondly, the critical indicators, theoretically, create a kind of virtuous circle of improvement. Forinstance, when indicator ' $X$ ' improves, it positively influences the improvement of other indicators, which will boost the enhancement of the indicator' $X$ 'again. 
4. Online Survey:This phase aimed to make a final selection of the indicators based on the participation of a broad kind of stakeholders involved in rural development. The 37 indicators (Figure 2) were assessed according to the characteristics of a good indicator described by M.J . Rigby, et al.,(2003) and the United Nations (2009): reliability, feasibility, relevance, completeness, comparability and sensitiveness. The participants rated the indicatorson a scale 1 to 5, where (1) was low level and (5) was high level.

Figure 2: Indicators Selected for the Global Survey

\section{INDICATORS OF GLOBAL SURVEY}

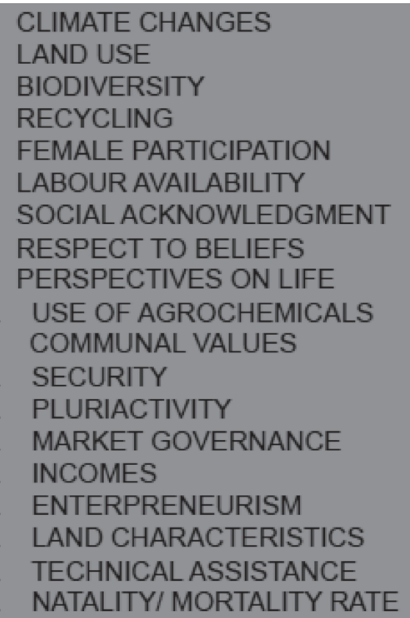

5. Selection of Participants: The participants of the online survey were organised into six different groups: peasants, professors, lecturers, students of a master in rural development, professionals and employees of public orprivateinstitutions focused on rural development. All the participants were chosen randomly. The selection of professors was made taking

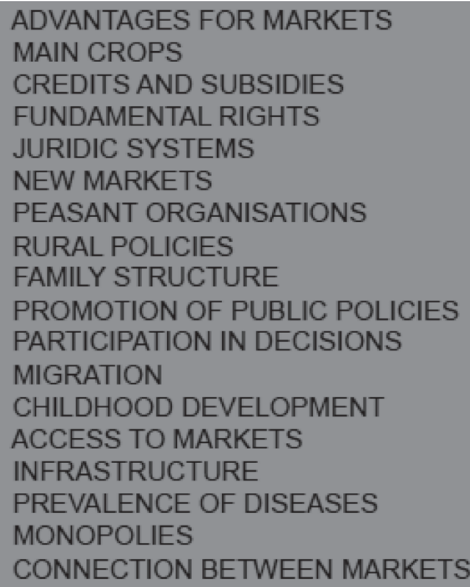

into account the authors of the papers consulted in the literature review (step 1) and other lecturers specialised in rural development. Studentsand professionals were selected from the websites of the universities. Peasants were chosen from the website of the international organisation 'La Vía Campesina' and employees were selected from the 
websites of public and privateinstitutions. At the end of the selection process, 1550 surveys were successfully delivered to people from 29 countries.

6. Statistical Analysis: The statistical methodology to find the indicators used two different criteria:

\section{A. A high score in the survey.Assuming that a grade of 3.0 is an acceptable level on a scale of 1 to 5 , were selected those indicators which achieved an average rating of 3.75 or greater on all the characteristics of a good indicator described previously (step 4).}

B. Principal Components Analysis. It is a multivariate techniquethat allows grouping of indicators according to the relationship among them. The method used to build different kinds of indices allows the assessment of the significance of complex matters. In this case, the selection takes into consideration the first six components. That means the indicators retain 7 per cent of the variance. The final indicators selected were those whose index was above 75 points on a scale from 0 to 100

7. Pilot Test and Final Selection: A pilot test was carried out in the city of Florian, in the State of Santander (Colombia). Five families participated in it. All the indicators were assessed according to their understanding. Equally, the best way to inquire sensitive topics such as domestic violence, female participation and the spending of incomes were evaluated.

\section{Results and Discussion}

190 respondents from 29 countries answered the online survey. Among the total respondents, 153 answered all thequestions. The statistical analysis was made based on the respondents who evaluated all the issues. In the current case, taking into account a total population size of 1550 people, 190 answers correspond to a confidence level of 95 per cent and a margin error of 6.7 percent. Nevertheless, from the total answers, 153 people answered all the questions; this number corresponds to a margin error of 7.5 per cent.

It is important to remark that similar researches conducted by electronic survey showed a similar participation rate. For instance, Miller (2001) got 54 answers in the first round of questions and 37 in the second one in a research where the goal was comparable to the current. He used the second series of a survey to identify the indicators of sustainable rural tourism. Analogously, Wang et al., (2003) got a total number of 126 answers in the study to classify the indicators of reproductive health for China's rural areas.

Even though other studies that used electronic survey as a methodology to gather information showed the highest rate of responses (Green et al., 2006; Kim, Gerber, Patel, Hollowell, $\&$ Bales, 2001), the current study combined a logic 
flow of steps to select from a broad range of factors, the most relevant topics according to the perception of several stakeholders related to rural development, including an expert group and people with different backgrounds.
At the end of the selection process, 23 indicators were chosen. Figure 3 shows all the indicators ordered according to the grade received.

Figure 3: Indicators Selected

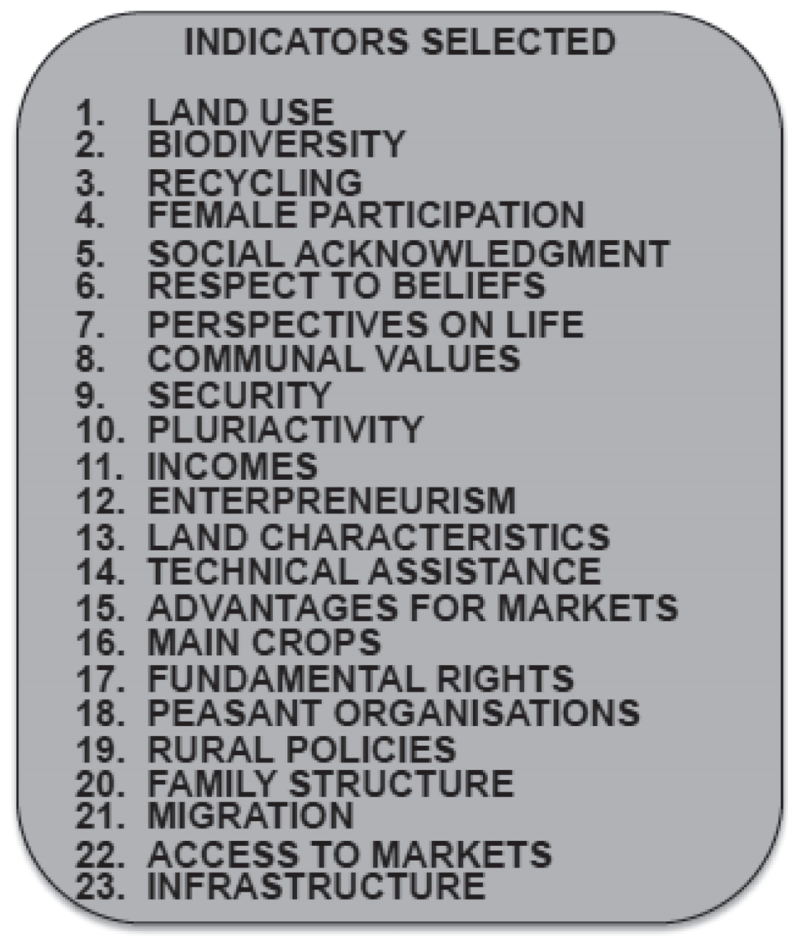

The indicators selected cover a broad range of rural development concerns, butbesides typical topics such as production level, technical assistance and enterpreneurism, the selection includes aspectsthat are usually forgotten in rural development studies which include social topics like participation of rural women, respect to social, spiritual and political beliefs by relatives and neighbours or the perspectives that the rural inhabitants have about their lives and future of the countryside.
Social acknowledgement is a crucial aspect included in the indicators. It refers to the recognition by the entire society about the significance that the rural society and its inhabitants have. The rural society's identity and its culture belongs to this indicator. Beyond the productive and economic topics, traditionally associated with rural development, the peasantry has recently called on the urban inhabitants to recognise its rights as members of the society (Desmarais, 2008; Rosset, 2003). 
Precisely, heritage of the peasantry framework recognises the importance of the rural identity and culture and at the same timeaims to verify,through the indicators selected, the aspects to enhance that peasants want to reach the goal of rural development, improving the quality of life and ensuring that the rights of all rural inhabitants are respected. Regarding these indicators, it is important to note two features. First, according to the number of heritages that the indicators belong, there are two kinds of them: simple and multiple. Simple indicators are those that belong to just one of the heritages and help to promote it. Multiple indicators are those that belong to more than one of the heritages. In essence, multiple indicators are synergistic. It means that these indicatorsimprove rural development in an integrated way.Second, the indicators aim to measure the top concerns of rural development-the supportive, conservative and inclusive topics. These themes seek to reach the rural development goal described previously.The supportive subjects are related to access to balanced markets, fair incomes, adequate infrastructure and so on. The conservation themes are related to ecological and environmental issues, which are strongly associated with rural activities and the production forms of the peasantry. Some examples are the concerns to care water,land, seeds or biodiversity. Finally, the inclusion subjects are related to the equity for the peasantry such as political issues and agrarian policies (health, welfare or education).

The indicators selected are organised according to the heritages of the peasantry analytical framework (described previously) as given below.

Cultural Heritage: The identity of the communities is the central feature of cultural heritage. It is intangible and is expressed mainly by the behaviours and manners of the peasantry according to theirtraditions and folklore. In other words, cultural heritage exalts the creativity of the peasants. In the case of cultural heritage, the indicators designated are biodiversity, female participation, family structure, migration, communal values and finally respect to beliefs. Figure 4 shows the principal features of each indicator. 
Figure 4: Indicators for Cultural Heritage

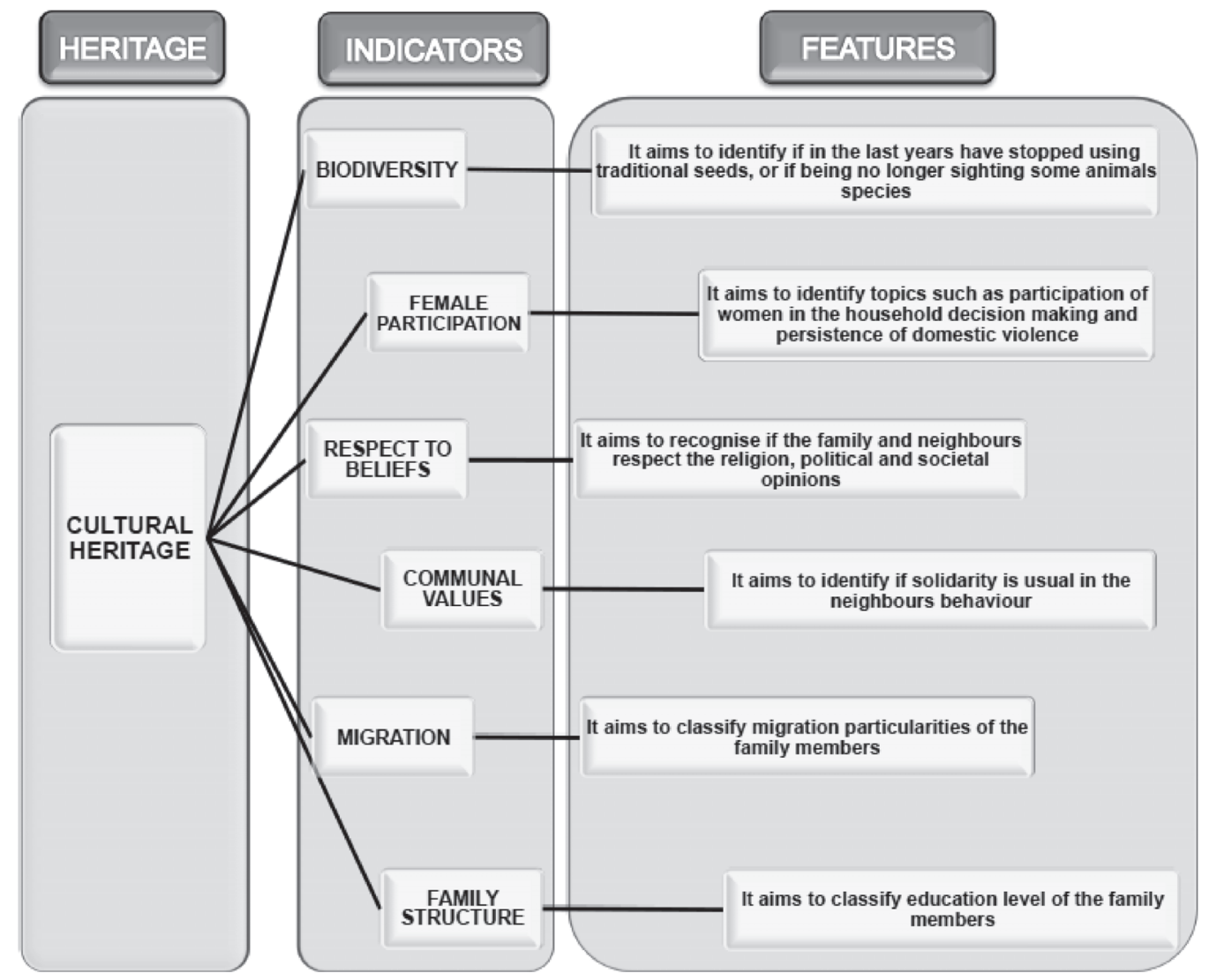

These indicators try to highlight the importance of heritages. In the case of cultural heritage, all the indicators aim to identify topics closely related to conservation of identity, behavioursand manners. Forinstance, biodiversity is essential for cultural heritage due to conservation of traditional seedsand endangered animal species. It could help to preserve how the peasantryacts.

Physical Heritage: Physical heritage is one of the most important means to improve life in rural areas. The presence or absence of good infrastructure could determine that a rural community remains isolated, without the likelihood to access the markets or establish permanent relationships with other communities. The availability of both public and private infrastructure, indeed, will allow improvement of quality of life of this community in different ways. Figure 5 shows the indicators (more narrowly) related to physical heritage. 
Figure 5: Indicators for Physical Heritage

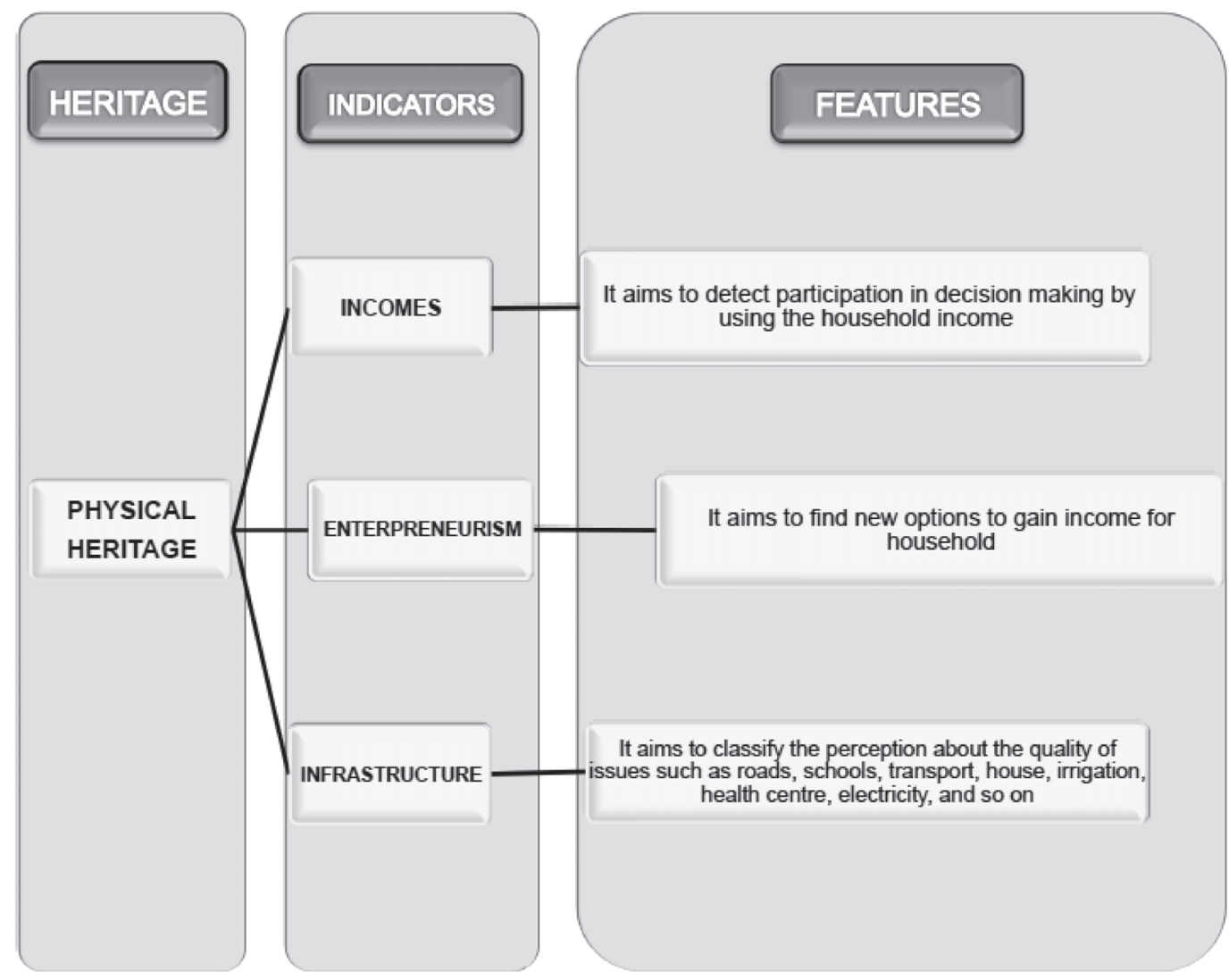

Undoubtedly, infrastructure is one of the most important indicators. In it, the aim is to try to establish the perception of a household about the described matters. However, it is important to compare their perceptions with the reality observed in the rural areas because, sometimes, perceptions could be different from the reality. For instance, a passable dirt road could be qualified as adequate or unusable, depending on the view point of the customer.Other indicators remarked are incomes and entrepreneurism. Obviously, family income is a crucial topic. However, it could be more interesting to find out the participation of household members at the moment to make a decision on how to spend the money. The reason is that money is more likely to be used to improve family constructions if women participate in the decision-making process.

Social Heritage: The base of social heritage is trust and ways to establish relationships with family members, colleaguesand neighbours; both individually and collectively. Belonging and participating in social networks will allow strengthening of the ties of trust, which will allow 
people to take part in collective actions looking for the improvement of quality of living. Figure 6 shows the seven selected indicators: female participation, social acknowledgement, respect to beliefs, fundamental rights, peasant organisations, family structure and migration.

Indeed, the role of women in generation of trust in a household is noteworthy. However, it is defined by the importance that women hold in the family. This issue is narrowly related to the acknowledgement of the importance of peasantry in the society as well as the deference to the diversity of viewpoints. Perhaps topicssuch as migration or family structure are commonly mentioned when social heritage matters are being discussed.The reason for it is family is the ground in which each member of the society initially interacts. The definition of future behaviour of an individual and its adequate integration into the society depends on the quality of these first relationships.

Figure 6: Indicators for Social Heritage

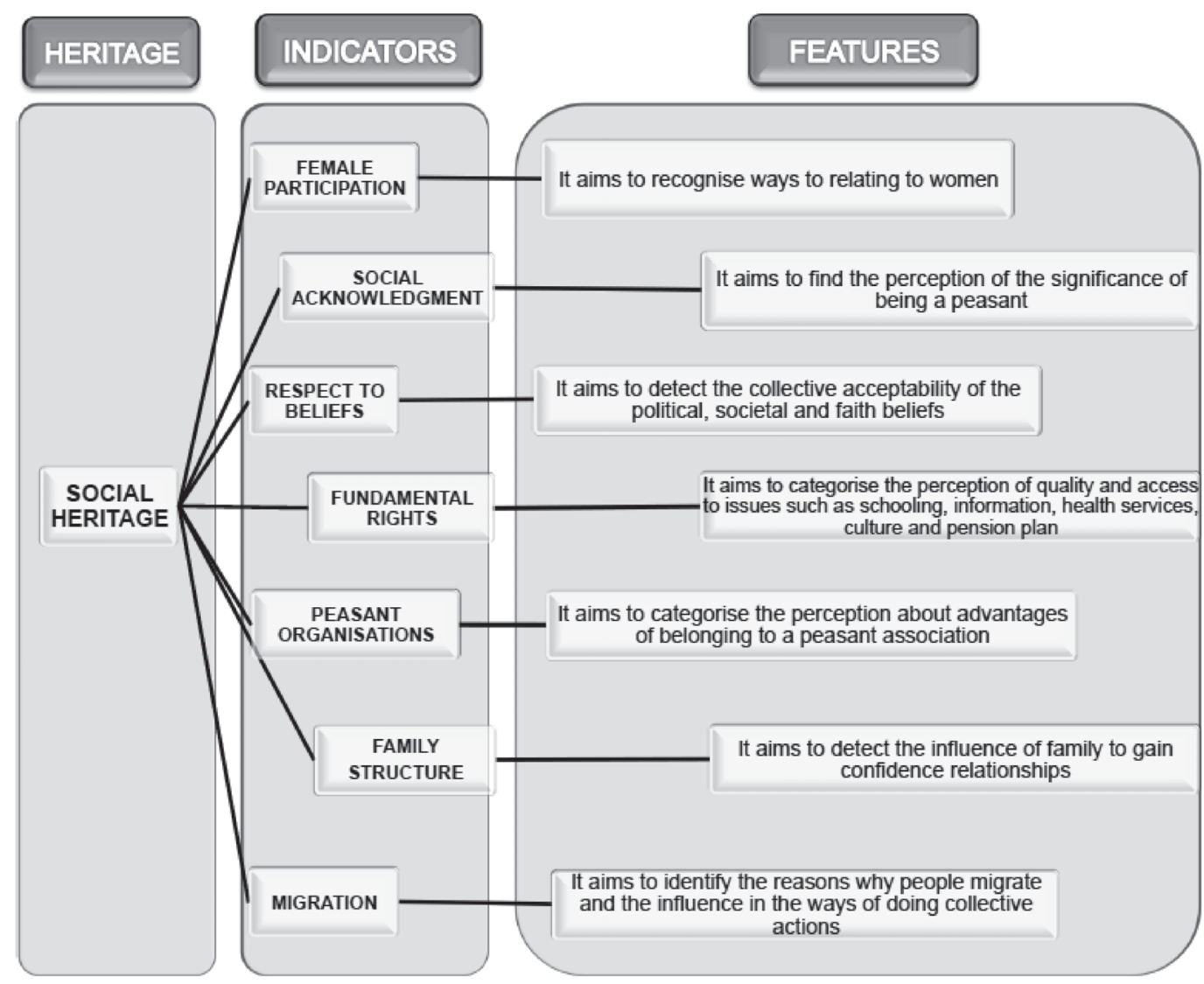


Institutional Heritage: It is obvious that the interaction of all heritages determines the improvement of the quality of life in rural areas. Precisely, institutional heritage focuses on normative ways to determine, construct and implement formal and informal rules. These rules organise ways of access to resources and power, in other words, self-regulation and social coexistence. Figure 7 describes the indicators selected:communal values, security, advantages for markets, main crops, peasant organisations, rural policies, and access to markets.

Figure 7: Indicators for Institutional Heritage

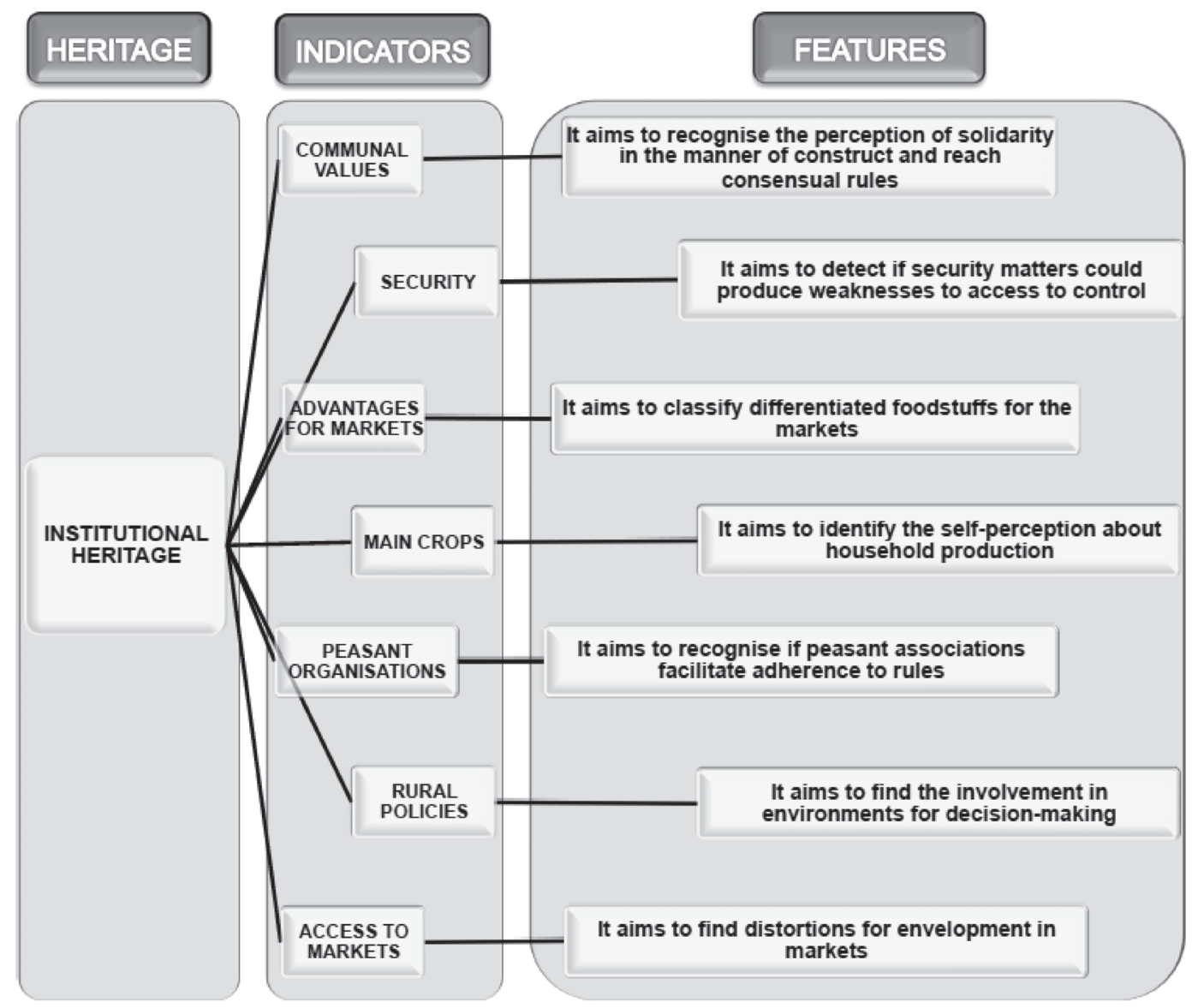

Some rules organise the participation of indicators into two different scenarios: public policies and markets; which perhaps are the most influential settings related to the improvement of quality of rural life. However, issues such as solidarity are on the ground of participation process. Indeed, a safe neighbourhood creates the best environment to participate in the creation of consensual rules.Safety,solidarity and confidenceallow, in conjunction with other topics, 
the participation in peasant organisations and involvement in the definition of rural policies. Atmospheres characterised by solidarity, collective work and respect to arrangements result in a favourable environment for market engagement.

Human Heritage: Human Heritage is directly related to knowledge, especially to traditional expertise.Thisissue isfundamental to rural areas because based on this understanding the new generations of peasants will safeguard some behaviours and manners. However, it is relevant to point out that some traditions are not worthy to follow, for instance, those related to domestic violence. In the sameway,the acknowledgement of traditions and folklore does not mean that cutting-edge production must be rejected. It is not a call for a Luddite tendency. On the contrary, the new technological advances must be mixed with the traditions to find out a reliable way to get things done, especially those that look for protecting the environment and traditions. In this scenario, Figure 8 shows the indicators selected: female participation, social acknowledgement, fundamental rights, rural policies and perspectives on life.

Figure 8: Indicators for Human Heritage

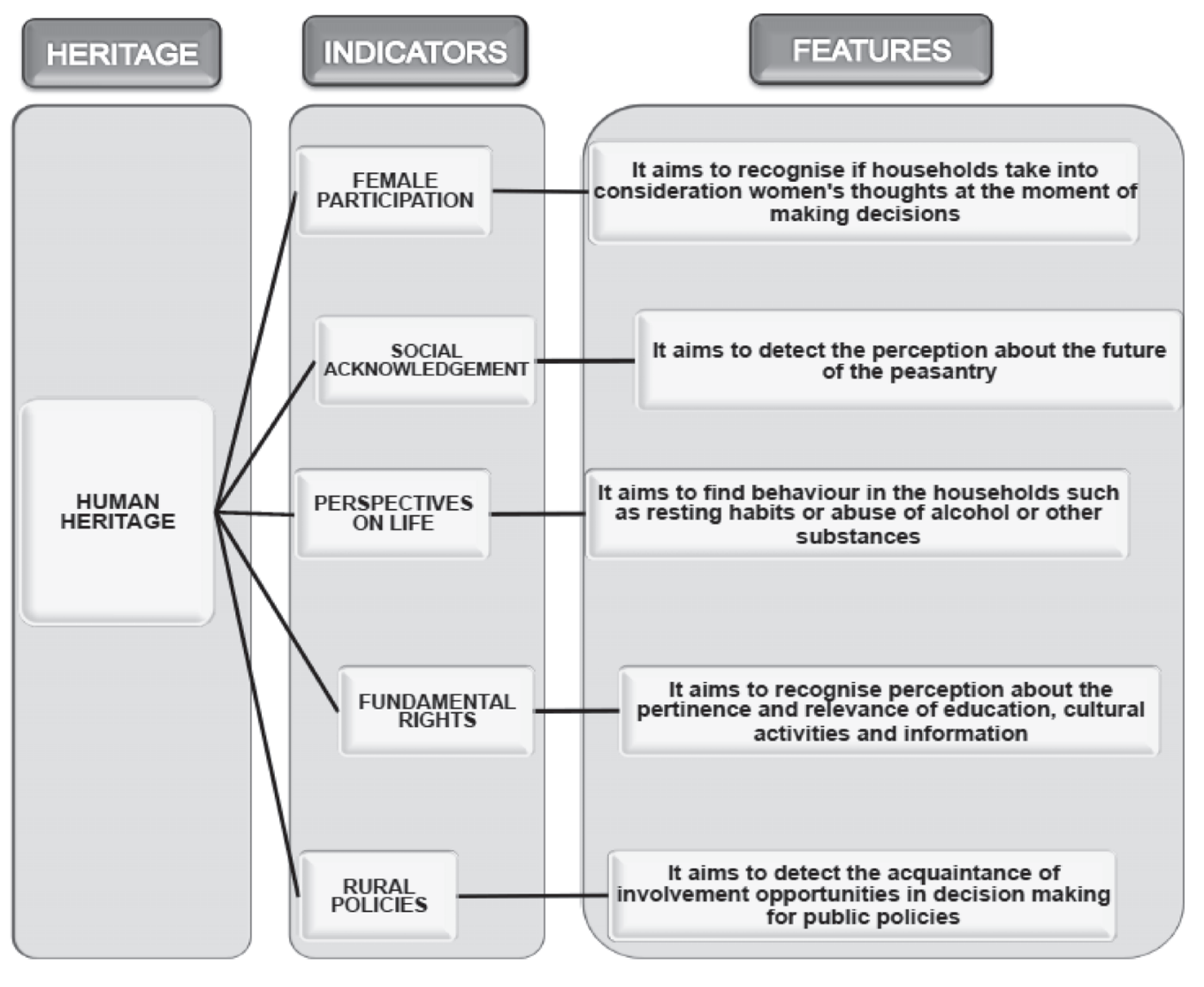

Journal of Rural Development, Vol. 36, No. 4, October-December : 2017 
The issues, commented by the indicators selected, try to find the role of women in the conservation and transmission of traditional knowledge. Equally, it takes into consideration the awareness of peasantry prospect, especially regarding rural policies. In thisscenario, access to education, information and culture by the peasantry allows the possibility of mixing traditional knowledge and last advances in technology.

Natural Heritage: Natural heritage maintains a narrow relation to those spaces where human intervention has not affected natural resources over time, so that current and future generations can appreciate and be sensitive to them. Natural heritage embraces landscapes, animal and vegetal species, seeds, water and other resources and natural phenomena such as the aurora borealis or water sky. Regarding natural heritage, it is important to remark topics such as biological resources and their use according to traditional knowledge, mainly looking for its preservation. Indeed, after the evidence of multi-functionality and pluriactivity of rural territories, natural heritage becomes as transcendental as productivematters.

Figure 9: Indicators for Natural Heritage

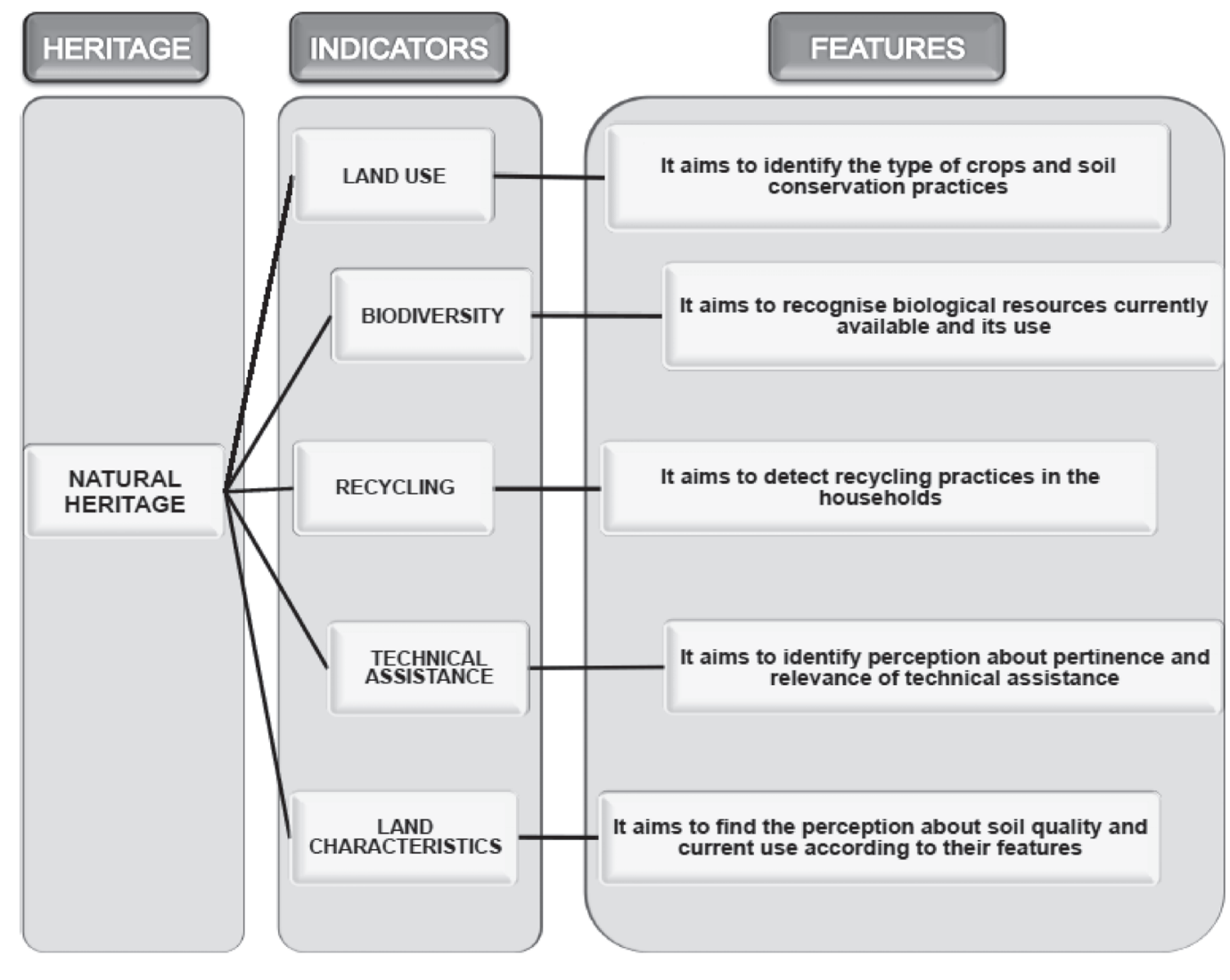

Journal of Rural Development, Vol. 36, No. 4, October- December : 2017 
Figure 9 shows the indicators selected for natural heritage:land use, biodiversity, recycling, technical assistance and land characteristics. Issues such as traditional ways to preserve and protect the soil and their features as well as the type of seeds used now-a-days to cultivate are remarked in the indicators selected. Biodiversity tries to identify if some seeds, as well as some animals, are no longer used or spotted in rural areas.Technical assistance could becomeacrucial matter to achieve the goal of protection of the biological resources available in rural areas.

Economic Heritage: Traditionally, economic growth has been privileged as the way to reach development. In rural areas, economic growth as a result of the increase of agriculture production has been the way in which the peasantry has reached success and hence improved its rural development level. However, this ap proach has not been holistic to understand the complexity of these matters. That is why the discussion about the ways to earn by labour is related to economic heritage; but especially the use of these economic resources to improve the quality of life of thehouseholds. Forthis purpose, economic heritage takes into consideration different topics. Figure 10 shows the indicators selected:security, pluriactivity, income, entrepreneurism, land characteristics, main crops, access to markets, technical assistance and advantages for markets.

Figure 10: Indicators for Economic Heritage

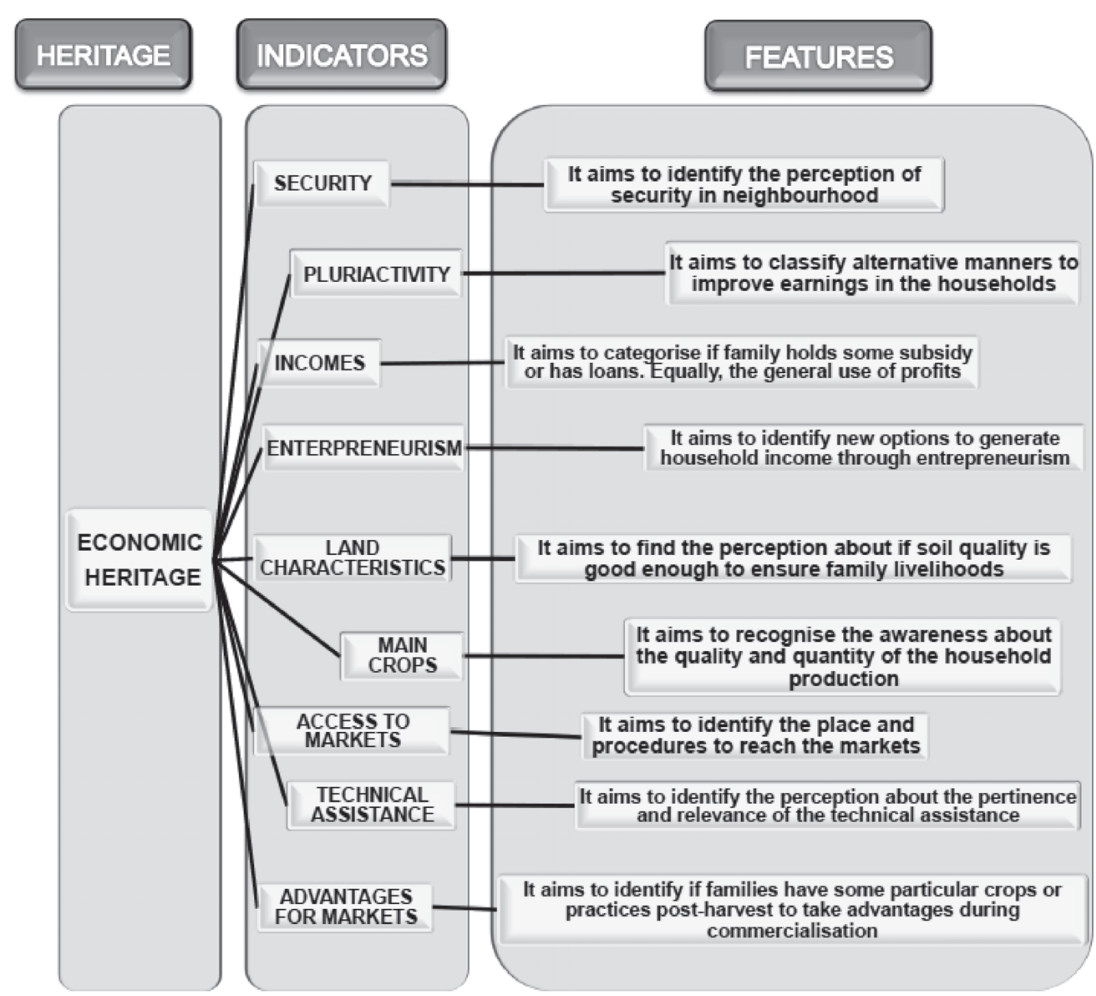


The indicatorshold particularemphasison productive practices as well as possibilities for the improvement of this production, such as prospects for associated work or operational support.The spending of income is a distinctive fact to improve the quality of life. That is why this matter is highlighted for the purpose of identifying the participation of household members in the making of these decisions.

\section{Conclusions}

From the methodological point of view, this paper described the method used to select basic indicators to evaluaterural development step bystep. The method took into consideration a wide group of stakeholdersinvolved in rural issues.That is why the indicators selected tried to covermany of the problems of rural issues in an eclectic way. The participation of several stakeholders from different contextsallowsthe indicators to become useful for rural areas from diverse backgrounds. Even though the methodology permits the participation of lot of people from different places and backgrounds, it excludes those that do not have access to internet connection or an email address. Similarly, more people can participate depending on the design of the survey, which must beattractiveand simple.
On theotherhand, itisimportantto remark that validation of these indicators is a new step in the research. Validating the indicators will allow other people concerned in rural development to use both the methodology and indicators to work in the countryside. These indicators are used to diagnose particular situationsat the household level, but at the same time, they can identify activities, either of public policy or family actions, to improve the quality of life and ensure respect forthe rights of rural people. In otherwords, they can be used to improve the rural development level.

At the end of the selection process, a question emerges: are these indicators usable everywhere? In other words, would the indicators be useful to measure rural development in a broad way in different places? An example is the way to enquire particular topics in various contexts, for instance, security or domestic violence issues in refugee settlements. Another distinction evidently is the availability of information in rural areas. However, both the analytical framework of heritages of the peasantryand itsindicators become an alternative to consolidate baseline information for rural territories.

Notes

The word peasantry is a generic and includes all the rural inhabitants: peasants, family farmers, shepherds, indigenous people, fishermen, landless people, pastoralists, artisans, rural workers and the like. 


\section{References}

Alfsen, K \& M, Greaker (2007), "From Natural Resources and Environmental Accounting to Construction of Indicators for Sustainable Development,"Ecol.Econ.,61 (4), 610. http://doi.org/10.1016/j.ecolecon.2006.06.017.

Barrios, E (2008), "Infrastructure and Rural Development: Household Perceptions on Rural Development," Prog.Plan., 70,44. http://doi.org/10.1016/j.progress.2008.04.001

Binder,C.R., Feola,G., \&J ,Steinberger (2010), "Considering the Normative, Systemic and Procedural Dimensions in Indicator-based Sustainability Sssessments in Agriculture,"Environmental Impact Assessment Review, 30 (2), 71-81.

Brown, V., J , Harris \& J ,Russell (2010), "Tackling Wicked Problems through the Transdisciplinary Imagination," Earthscan, p. 312.

Bryden, J., A, Copus., \& M, MacLeod (2002),"Rural Development Indicators (Vol. 1)," Luxemburg: EUROSTAT.

Caschili, S., A, De Montis, \& D, Trogu (2014), "Accessibility and Rurality Indicators for Regional Development," Comput. Environ. Urban Syst., 49, 114. http://doi.org/10.1016/j.compenvurbsys.2014.05.005.

Ciegis, R., J, Ramanauskiene, \& G, Startiene. (2015), "Theoretical Reasoning of the Use of Indicators and Indices for Sustainable Development Assessment," Engineering Economics, 63 (4).

Cole, A (2006), “The Influence Matrix Methodology: A Technical Report,"Landcare Research Contract Report: LC0506/175.

Correa, V.,F, Silva \&H, Neder (2008), “Construção De Um Índice De Desenvolvimento Rural - Resultados Para As Regiões Nordeste E Sul Do Brasil," Sociedade Brasileira de Economia, Administracao e Sociologia Rural (SOBER).

Cowell, S., \& S, Parkinson (2003), "Localisation of UK Food Production: An Analysis Using Land Area and Energy as Indicators," Agric. Ecosyst. Environ., 94 (2), 236.

Desmarais, A (2008), "The Power of Peasants: Reflections on the Meanings of La Via Campesina," The Journal of Peasant Studies, 24 (2), 138-149. http://dx.doi.org/10.1016/j.jrurstud.2007.12.002.

Farrow, A., \& M , Winograd, (2001), “Land Use Modelling at the Regional Scale:An Input to Rural Sustainability Indicators for Central America," Agric. Ecosyst. Environ., 85 (1-3), 268.

Green, V.A., K, Pituch.,J , Itchon., A, Choi., M,O'Reilly., \&J, Sigafoos (2006), "Internet Survey of Treatments Used by Parents of Children with Autism," Research in Developmental Disabilities, 27 (1), 70-84. http://doi.org/ 10.1016/j.ridd 2004.12 .002 .

Ilskog, E (2008), "Indicators for Assessment of Rural Electrification - An Approach for the Comparison of Apples and Pears,"Energy Policy, 36 (7),2673. http://doi.org/10.1016/j.enpol.2008.03.023.

Kageyama, A (2004), “Desenvolvimento Rural: Conceito e Medida,” Cadernos de Ciência \& Tecnologia, 21 (3), 379-408.

Kim, H., G, Gerber., R, Patel., C, Hollowell \& G, Bales (2001), "Practice Patterns in the Treatment of Female Urinary Incontinence: A Postal and InternetS," Urology, 57 (1), 45-48. http://doi.org/10.1016/S00904295(00)00885-2.

Journal of Rural Development, Vol. 36, No. 4, October-December : 2017 
Landeta,J (2006), "Current Validity of the Delphi Method in Social Sciences, Technological Forecasting and Social Change, 73 (5), 467-482. http://doi.org/10.1016/j.techfore.2005.09.002.

Lehtonen, M (2008), "Mainstreaming Sustainable Development in the OECD through Indicators and Peer Reviews, Sustainable Development, 16 (4), 241-250.

Linstone, H., \& M, Turoff (2006), "The Delphi Method: Techniques and Applications," Retrieved March 29 (2002), p. 616

Melo, C., \& J, Parré (2007), “Índice De Desenvolvimento Rural Dos Municípios Paranaenses: Determinantes e Hierarquização," Revista de Economia ESociologia Rural, 45 (2).

Miller, G (2001), “The Development of Indicators for Sustainable Tourism: Results of a Delphi Survey of Tourism Researchers,"Tourism Management,22 (4),351-362.

Mittenzwei,K.,W,Fjellstad.,W,Dramstad.,O,Flaten.,A,Gjertsen.,M,Loureiro \&S,Prestegard (2007),“Opportunities and Limitations in Assessing the Multifunctionality of Agriculture within the CAPRI Model, Ecol. Indic., 7 (4), 838. http://doi.org/10.1016/j.ecolind.2006.10.002.

Okoli, C., \& S, Pawlowski, (2004), “The Delphi Method as a Research Tool:An Example, Design Considerations and Applications," Information \& Management, 42 (1), 15-29. http://doi.org/10.1016/j.im.2003.11.002.

Pachón F; W, Bokelmann \& C, Ramírez (2016a), "Heritages of the Peasantry: An Analytical Framework to Address Rural Development," 4th Nordic Congress of Rural Research, Akureyri, Iceland.

Pachón F; W, Bokelmann \& C, Ramírez (2016b), “Rural Development Thinking, Moving from Green Revolution to Food Sovereignty, Agronomía Colombiana, In Press.

Rigby, D., P, Woodhouse., T, Young \& M, Burton (2001), “Constructing a Farm Level Indicator of Sustainable Agricultural Practice," Ecol. Econ., 39 (3), 478.

Rigby,M., L, Köhler., M , Blair \& R, Metchler (2003), “Child Health Indicators for Europe,”The European Journal of Public Health, 13 (suppl 1), 38-46.

Rosset,P (2003),"Food Sovereignty:Global Rallying Cry of Farmer Movements,"Food First Backgrounder, 9 (4), 1-4.

Rossing,W., P,Zander., E,J osien., J, Groot., B, M eyer \& A, Knierim (2007), "Integrative Modelling Approaches for Analysis of Impact of Multifunctional Agriculture: A Review for France, Germany and The Netherlands," Agric. Ecosyst. Environ., 120 (1), 57. http://doi.org/10.1016/j.agee.2006.05.031.

Schultink, G (2000), "Critical Environmental Indicators: Performance Indices and Assessment Models for Sustainable Rural Development Planning, Ecol. Model, 130 (1-3), 58.

Shen, L., S, Jiang \& H, Yuan (2012), "Critical Indicators for Assessing the Contribution of Infrastructure Projects to Coordinated Urban-Rural Development in China," Habitat Int., 36 (2), 246. http://doi.org/10.1016/ j.habitatint.2011.10.003.

United Nations (2009), "Indicators on Rural Development and Agriculture Household Income," Economic and Social Commission for Western Asia (ESCWA), Beirut.

Wang, C., Y, Wang., K, Zhang., J, Fang., W, Liu., S, Luo., V, Li (2003), “Reproductive Health Indicators for China's Rural Areas," Social Science \& Medicine, 57 (2), 217-225.

World Bank (2000), “Rural Development Indicators Handbook," Washington D.C. 